\title{
El proceso de generación de pensamiento
}

\author{
Yolanda Isaura Lara García \\ Universidad Pedagógica Nacional en el estado de Chihuahua \\ yolislara_1@hotmail.com
}

\begin{abstract}
Resumen
Este articulo está basado en la investigación bibliográfica realizada en el marco del trabajo de doctorado, en "Investigaciones Educativas" con fines de elaboración de la tesis de grado. Esta última, tiene como objetivo generar conocimiento teórico-gnoseológico sobre "El proceso de generación de pensamiento" desde los cuatro modos de apropiación de la realidad, abordados por Aristóteles, Marx, Engels, Nietzsche, Frazer, Fromm, Covarrubias entre otros; sus conceptos son: lo empírico; la magia y religión; el arte y la teoría. En cada uno de estos modos de apropiación de la realidad, se revelan sus elementos constitutivos destacándose entre ellos: el proceso de constitución de conciencia; el carácter de los referentes y, la construcción de figuras de pensamiento. Cada uno, potencializa la edificación de categorías analíticas para su reflexión. Dichas aportaciones teóricas discuten a la vez que analizan el concepto de conciencia acuñado por Hegel, revisado y teorizado por diferentes filósofos a lo largo de la historia posibilitando nuevos problemas de indagación e investigación sobre la misma formación de la ciudadanía; la conformación de sujetos individuales y sociales; el estatuto gnoseológico y epistemológico en el modo de pensar y actuar; en fin, la cimentación de la sociedad. Asimismo, el carácter de los referentes, entendiéndose a estos como los nutrientes de cada modo de apropiación de la realidad, suscita un razonamiento, una disertación, así como un andamio teórico-conceptual en los esquemas y las estructuras de las imágenes y figuras de pensamiento en el individuo y la colectividad.
\end{abstract}

\section{Palabras claves}

Conciencia, empiria, magia-religión, arte, teoría.

\section{El proceso de constitución de conciencia}

La revisión específica del soporte filosófico sustentado en la obra de Hegel, expresa que nada estático, ni inamovible puede versarse en el concepto de dinámica y dialéctica mencionándose el siguiente argumento: "El capullo desaparece al abrirse la flor, y podría decirse que aquél es refutado por ésta; del mismo modo que el fruto hace aparecer la flor como un falso ser allí de la planta, mostrándose como la verdad de ésta en vez de aquélla. Estas formas no sólo se distinguen entre sí, sino que se eliminan las unas a las otras como incompatibles." (Hegel, 1978: 8) De igual manera, la conciencia, como un modo de apropiación de la realidad, propio de la naturaleza humana, se encuentra en un proceso de edificación y conformación mediante las relaciones que el ser vive en la sociedad, a partir de la cual piensa y 
siente, dentro de la cual le ha tocado nacer, vivir, reproducirse y morir.

Esta sociedad capitalista, esclavista del consumismo, neoliberal, la que le dicta al ser humano lo que le está permitido ser y hacer o lo que le está prohibido ser, al mismo tiempo que le dice que dejar de hacer, de tal modo que lo que él/ella es, su exteriorización; lo que se observa en la realidad, no debiera ser lo que piensa que es, sin embargo, lo es. Se vive como se piensa y se piensa como se vive. Y bien, si la conciencia sólo sabe y concibe que existe gracias a lo que está presente en su experiencia; entonces, resulta de interés académico indagar ¿qué está en la cuna de su pensamiento como conciencia? Coincidiéndose que en la vida cotidiana, dicha conciencia está repleta de conocimientos, experiencias, concreciones sensibles de igual manera que pensamientos y principios que se encuentran fijos y estables.

Conviene esbozar ahora, la terminología del ser en sí y, el ser para sí, como los elementos íntegramente constitutivos de la concepción ontológica, gnoseológica y teleológica requerida para la organización del modo de apropiación de la realidad. Los cuatro modos en que el ser humano se apropia de la realidad, son las maneras diferentes en las que conoce, de ahí, la forma en la cual se construye el conocimiento y no lo que realmente se está conociendo. Nunca se conoce la realidad como tal, sino mediante las representaciones de pensar esa realidad.

\section{Modo de apropiación de la realidad empírico, pragmático y utilitario}

¿Con qué herramientas mentales el ser humano ordinario, común y sencillo, se apropia de lo real? Habrá de argumentarse que la apropiación de la realidad en la conciencia empírica se genera vía su forma de vivir y coexistir en ella percibiéndola como una realidad externa a sí mismo, esto es lo que establece en su existencia una separatidad que simultáneamente promueve un aislamiento y una fragmentación en la integridad del individuo; ello, lo lleva a creer que sus sensaciones, sus sentimientos y sus costumbres derivados de esa realidad externa, centralizada exclusivamente en el sentir, fuera de toda posibilidad de pensar, reflexionar y hacer en consecuencia, es la única vida que posee.

Esos sentimientos y esos valores que se articulan en imaginarios $y$ representaciones mentales se transforman en saberes y prácticas culturales instituyéndose en formas de vida unidimensionales. La sociedad actual, industrializada y cerrada donde la única posibilidad de vida es el adoctrinamiento, mediante un proceso de mecanización, de reflejo y de automatismo donde se reprime la individualidad como concreción de libertad pensante, no potencializa ni la intención tiene de hacerlo de evidenciar alguna alternativa hacia la reflexión y el análisis de esa forma de vida. Por el contrario, en esta sociedad el ser humano no cuenta con la herramienta conceptual de la crítica; cuando un individuo se encuentra a sí mismo considerándose que él es en sí, según las cosas que vive y siente, entonces, esas cosas dan forma y sentido a su vida cosificándolo, pues acepta todo lo externo a él como ley, como algo rígido e inamovible. Se vive en una cultura de elementos mercantilizados, así, la conciencia empírica es una conciencia de felicidad falseada, este individuo de la actual 'sociedad del bienestar feliz' cree que todo está bien, no tiene remordimientos y es conformista, por lo tanto, no hay en él posibilidad de contradicciones. No existe la fuerza de 
contradicción racional, de negación contradictoria.

¿Por qué son unidimensionales tanto la realidad actual como el ser humano que vive en ella? Porque no existen diferencias entre lo que la humanidad cree como verdad y la realidad misma como proceso de construcción social, además, no hay distinción entre lo que es el mundo y lo que 'soy yo', es un solo marasmo de ideas. La humanidad unidimensional no puede elaborar críticas, no alcanza a visualizar la diferencia entre lo real para apropiarse y la idea de dicha adjudicación. La única manera de acercarse a la apropiación de la realidad es mediante el pensamiento positivista bajo el dominio del poder tecnológizado. La vida del ser humano sencillo y simple se reduce a la conservación y permanencia en el uso de los instrumentos de comunicación celular, de los medios masivos de comunicación y de las redes sociales que lo mantienen ocupado, enajenado en una sola palabra, para la continuidad y persistencia que cohesiona la lógica del poderío tecnológico.

El espíritu que se revela tan pobre, ejemplificado como un peregrino en el desierto suspira y fallece tan sólo por una gota de agua, aquella con la cual confortarse y consolarse; desde este cristal analítico, se distingue lo poco, o casi nada que necesita para sentirse contento; dándose cuenta de la inmensidad que no se reflexiona, que no se analiza, que no se interpreta, que no es potencializada, que es desperdiciada por la mediación de lo utilitario. No es más que la concepción de la conciencia pragmática, o bien, la de una conciencia empírica que no ve o que no es capaz de entender y analizar más allá de donde sus ojos se ubican. El yo es un 'yo' vacuo y escueto, por ello no sobrepasa su ser para 'si'. Esta inmediatez simple constituye la verdad del ser, se es solamente porque se existe. Se siente lo que se siente y con base en eso que se siente es que se actúa. Aquí, lo único verdadero de la certeza sensible, es esencialmente lo único que está frente a este modo de apropiación de la realidad.

A la conciencia empírica no le interesa el pensamiento de autores como Kant, Hegel y Marx, por el contrario, se le dificulta pretender entender su manera de pensar. Porque "...la teoría kantiana vive como andamiaje categorial en las conciencias cultas y como cotidianidad existencial burguesa en todos los sujetos; la teoría hegeliana está hoy en las conciencias cultas solamente y; la teoría marxista vive en las conciencias críticas cultas e ingenuas. En cambio, los nombres de los personajes políticos son recordados por muchos, pero a muy pocos interesa su pensamiento y a todos el hecho específico en el que participaron." (Covarrubias, 2002:8) Entonces, ¿a quién la interesa conocer y actuar en su realidad? Esto, no es una característica específica de las conciencias prácticas y utilitarias.

El tránsito de una conciencia 'empírica' a una 'teorizante' es un proceso lento, arduo $\mathrm{y}$, sinuoso en el que la interrogante hace presencia en el diario vivir, sin dejar de ir y venir en la reflexión. Lo que constituye su centro en un accionar dialéctico, en un movimiento constante, en una incesante transformación y mutación permanente, en una palabra, su metamorfosis.

\section{Modo de apropiación de la realidad mágico-religiosa.}

Para argumentar el modo de apropiación de la realidad mágico-religiosa resulta necesario tomar como referencia tanto su proceso histórico-filosófico de concreción, así como el transcurrir psicológico de la fe, desde los primeros ejercicios de evangelización. Lo mismo que para 
analizar la concepción de la raíz y el origen de dicha conciencia, no basta con examinar su presupuesto dogmático; se requiere deliberar sobre las creencias acunadas en la magia como la razón de ser del dogma, tanto en la colectividad y no sólo, desde el aposento individualista. (Fromm, 1994:9) "...la evolución del dogma sólo se puede comprender mediante el conocimiento del inconsciente, sobre el cual ejerce su efecto la realidad externa y que es el que determina el contenido de la conciencia."

Si la esencia de la religión fluye desde el animismo $y$, junto a él, la perspectiva totémica; ha de conceptualizarse como testimonio, la confianza que el hombre tiene en la magia como poder para dominar la naturaleza de modo directo; por ello, la magia, se emparéntela con la ciencia. La religión por su parte, demuestra la confesión de impotencia humana en cuestiones específicas y eleva a la humanidad al nivel de lo mágico y lo sobrenatural. La magia surge de las tradiciones. Ella, vive en y del misticismo. Por su parte, la religión se centra ante la imposibilidad del ser humano de resolver sus necesidades físicas, humanas, sociales y emocionales, considerándolas a todas y cada una de ellas como circunstancias más grandes que sus propias fuerzas; en el modo de apropiación de la realidad desde la concepción mágico-religiosa, tanto la magia como la religión son manifestaciones de las conductas de la humanidad a través de una actitud pragmática creada vía la razón y, paralelo a ella la voluntad y el sentimiento.

La magia y la religión están unidas mediante una relación filosófica profunda, sobre la relación de la vida del hombre con la vida de la naturaleza; pero sobre todo en una filosofía triste que origina ideas trágicas. Se aduce a las explicaciones expresadas por Fromm (1994) al hablar de la encarnación del ser supuestamente divino en el hombre sencillo y común con lo que se le conceptualiza 'hombre-dios'. Donde de igual manera pueden discutirse varios tipos de magia entre los que se encuentran la inmediata o directa 'de contacto' o 'contagio' así como la homeopática basada en la asociación de ideas por contigüidad. Del mismo modo que la magia es considerada ciencia falsa $y$ arte abortado, es por lo que no se coincide con ninguna de esas dos categorías en términos de Frazer (2008). La figura de pensamiento que aparece reiteradamente es la de la atracción de las cosas similares basada en la idea de magia homeopática. Los referentes constitutivos de la religión se ostentan desde la fe como la forma de obrar gobernada por un temor al ser sobrenatural constituido por sí mismo.

Temor surgido ante circunstancias de difícil entendimiento en la vida. Así, el ser humano que se apropia de la realidad bajo una concepción mágico-religiosa carente de un conocimiento totalizador, se ubica en buscar diariamente evitar el sufrimiento-dolor independientemente que esto le obligue a ver y concebir su realidad ya pensada de otra manera, ahora, visualizada diferente, centralizada y enfocada en esa esperanza de que sucederá algo mejor. Todas estas edificaciones se encuentran estratificadas como figuras imaginarias. Así lo muestran las siguientes interrogantes: ¿El ser humano puede en algún momento de su infancia sentirse igual de poderoso que su padre para evitar la sensación de desvalido? ¿Acaso el ser humano a lo largo de toda la vida puede sentirse como un niño aun siendo un adulto? Entonces, ¿qué es la religión? Sino una concreción del pensamiento infantil de la humanidad. 
Modo de apropiación de la realidad artístico.

¿A quién ha interesado alojarse en el estudio del componente artístico en los modos de apropiación de la realidad? Los que destacan, son el mismo Aristóteles, Freud, Marx, Vattimo y, Nietzsche entre algunos. En palabras del psicoanalista (Freud, 2000: 79) "Lo que tan poderosamente nos impresiona no puede ser, [...] más que la intención del artista en cuanto él mismo ha logrado expresarla en la obra y hacérnosla aprehensible. [...] no puede tratarse tan sólo de una aprehensión meramente intelectual; ha de ser suscitada también nuevamente en nosotros aquella situación afectiva, aquella constelación psíquica que engendró en el artista la energía impulsora de la creación." Las obras artísticas no sólo son una manifestación más de lo que el ser humano es, sino, la expresión concreta y potenciadora de la realidad en su conjunto. Toda expresión artística en la humanidad, cobra vida, relieve y exposición en el sentido real como en el inconsciente dentro del ser humano ya sea a través de la música, la poesía, la pintura, o la escultura. Así, la obra de arte, entendida como un producto con base en las herramientas de su productor y, de la realidad contextual mediatizada, permite concebir un punto interesante a deliberar siendo éste, la creación del autor a partir de todas sus fantasías o bien de todas las experiencias que en su vida ha tenido por razón de ese largo recorrer y transitar. Ciertamente, toda obra de arte pertenece a un tiempo y un espacio; a una tradición y un lenguaje; en fin, a un horizonte común en el que se prolonga.

Argumentando la expresión de (Vattimo, 1995: 113) puede citarse: "A diferencia, de las manufacturas útiles, la obra de arte muestra su carácter terrestre, su mortalidad, su manera de estar

El proceso de generación de pensamiento sometida a la acción del tiempo." Y, si la obra de arte, es "...también siempre un 'símbolo' de la cuestión del nacimiento y de la muerte es algo que la interpretación y el discurso crítico no logran articular", cabe anteponerse la posición y el debate teórico manifestado no sólo por Marx y Engels, sino por algunos otros teóricos como Nietzsche dentro del proceso nihilista y destructor de la misma humanidad, ya no sólo de las creaciones artísticas por ella realizadas, sino de la esencia misma del sujeto como ser individual y ser social.

Marx, (1965: 26) especifica: "...la situación del arte en la sociedad capitalista. Se desenvolvió su desarrollo en condiciones desfavorables, bajo el yugo de la esclavitud capitalista, en lucha Contra el medio circundante. Esta lucha engendró sus formas especiales de creación y enseñó al artista, [...] a «buscar la medicina en el propio mal»; ella misma constituye de por sí un grandioso avance en la historia del arte $\mathrm{o}$, por lo menos, de algunos de sus tipos y posibilidades. [...] otros tipos de actividad artística pertenecen al pasado. «En cuanto a algunas formas del arte, como la poesía épica, se ha reconocido incluso que, en su forma clásica, que hizo época en la historia mundial, jamás hubieran podido crearse en cuanto empezó la producción artística como tal; de tal modo que, en la esfera del propio 'arte', ciertas formas que tienen enorme importancia, sólo son posibles en un grado relativamente bajo de desarrollo artístico. "Puede cuestionarse, si las fuerzas están destinas a la productividad y a la generación de la plusvalía, ¿por qué habría de favorecerse la consolidación de piezas artísticas? Con ello, cada una de las victorias del arte se compra al precio de la pérdida de la calidad moral. Y como todo en la sociedad, cuando ella se encuentra en crisis, la realidad de manera concreta y 
tangible se encuentra en crisis, así todos los tejidos sociales y existenciales también, la misma suerte engendra el modo de apropiación de la realidad artístico.

\section{Modo de apropiación de la realidad teórica.}

El conocimiento no es el reflejo de sí mismo como contenido, que hace despertar a la verdad, sino la esencia misma de esa verdad que ha sido aprehendida y apropiada en el sujeto por él mismo. Para Hegel, "El conocimiento científico, [...] exige entregarse a la vida del objeto o, lo que es lo mismo, tener ante sí y expresar la necesidad interna de él. Al sumergirse así en su objeto, este conocimiento se olvida de aquella visión general que no es más que la reflexión de saber en sí mismo, fuera de contenido." (Hegel, 1978: 36) Por ello, el conocimiento, es la característica propia del modo de apropiación de la realidad teórica.

Covarrubias expone que "La práctica teorizante se diferencia de las prácticas artística, empírica y mágico/religiosa en que se realiza bajo el predominio de la razón, haciendo uso de categorías y construyendo conceptos. Esto implica que los referentes ateóricos integrados a la conciencia teorizante, operen sometidos a la lógica establecida por los referentes teóricos, que son los que establecen las condiciones de su funcionamiento." (Covarrubias, 2002:14) ¿Cómo el individuo situado en el modo de apropiación teórico de la realidad se apropia de ella? ¿Cómo el individuo centrado en el modo de apropiación teórico de la realidad piensa lo real? ¿Cómo el individuo ubicado en ese modo de apropiación teórico se explica lo real? Cada uno de ellos tiene que ver con la lógica ontológica y gnoseológica del objeto real que ahora se construye en un objeto de entendimiento $y$ por ello de conocimiento.

Válido y conveniente resulta el supuesto que el mayor nihilista en el siglo XIX expone sobre el sujeto ubicado en el modo de apropiación de la realidad teórico, (Nietzsche, 2003: 275) "...es un hombre que constantemente vive, ve, oye, sospecha, espera, sueña cosas extraordinarias; alguien al que sus propios pensamientos golpean como desde fuera, como desde arriba y desde abajo, constituyendo su especie peculiar de acontecimientos y rayos; acaso él mismo sea una tormenta que camina grávida de nuevos rayos; un hombre fatal, rodeado siempre de truenos y gruñidos y aullidos y acontecimientos inquietantes. Un [...] ser que con frecuencia huye de sí mismo, que con frecuencia se tiene miedo a sí mismo, pero que es demasiado curioso para no «volver a sí mismo» una y otra vez..." Y que lleva a concluir estas expresiones y presupuestos teóricos haciendo uso de la idea de Aristóteles: "...somos lo que hacemos día a día. De modo que la excelencia no es un acto, sino un hábito. "

\section{Referencias}

Covarrubias Villa, Francisco. Las herramientas de la razón, ed. UPN: México; 1995, 277 pp. Covarrubias Villa, Francisco. La otredad del yo. (El hombre cosa de la sociedad capitalista). ed. Colegio de Investigadores en Educación de Oaxaca: Oaxaca; 2001, Col. Teoría, No. 4.

Covarrubias Villa, Francisco. $L a$ generación histórica del sujeto individual, ed. UPN: México; 2002, Col. Textos, No. 32.

Freud, S. Tótem y Tabú, ed. Alianza Editorial: Madrid; 2000, Col. El 
libro del bolsillo, 165 pp. Freud, S. Psicoanálisis del arte, ed. Alianza: Madrid; 2000.

Frazer, James George. La Rama Dorada magia y religión, TOMO I, editorial de Ciencias Sociales; La Habana Cuba: 2008.

Fromm, E. El dogma de Cristo, ed. Paidós: Barcelona; 1994, 68 pp. Hegel, G. W. F. Fenomenología del espíritu, ed. FCE: México; 1978.

Marx, C., Engels, F., Justo, Juan B. Religión
(Ideario), ed. Siglo XXI editores: México; 1997.

Marx, C y Engels, F. Sobre la literatura y el arte, ed. Política: La Habana, Cuba; 1965. Pp. 470. Nietzsche, F. Más allá del Bien y del Mal, ed. Tomo: México; 2003.

Vattimo, Gianni. EL FIN DE LA MODERNIDAD Nihilismo $y$ hermenéutica en la cultura posmoderna, ed. Gedisa: España; 1995. 
RECIE. Revista Electrónica Científica de Investigación Educativa

Vol. 1, núm. 1, enero-diciembre 2012, pp. 63-69. 